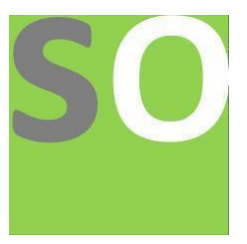

Article title: Evaluation of Department Head Person Based on Gender, Gender Role Orientation, and Attachment of Labels in Dire Dawa University

Authors: Mustefa Jibril[1]

Affiliations: Dire Dawa University, Dire Dawa, Ethiopia[1]

Orcid ids: 0000-0002-3165-2410[1]

Contact e-mail: mustefazinet1981@gmail.com

License information: This work has been published open access under Creative Commons Attribution License http://creativecommons.org/licenses/by/4.0/, which permits unrestricted use, distribution, and reproduction in any medium, provided the original work is properly cited. Conditions, terms of use and publishing policy can be found at https://www.scienceopen.com/.

Preprint statement: This article is a preprint and has not been peer-reviewed, under consideration and submitted to ScienceOpen Preprints for open peer review.

DOI: 10.14293/S2199-1006.1.SOR-.PPCCOAQ.v1

Preprint first posted online: 16 July 2021

Keywords: Gender, gender role, Dire Dawa, evaluation, Department head. 


\title{
Evaluation of Department Head Person Based on Gender, Gender Role Orientation, and Attachment of Labels in Dire Dawa University
}

\author{
Mustefa JIBRIL \\ School of Electrical \& Computer Engineering, Dire Dawa Institute of Technology, Dire Dawa, \\ Ethiopia \\ mustefa.jibril@ddu.edu.et
}

\begin{abstract}
The study, designed to find out the gender outcome, gender roles, and labeling of labels in the department's head examination, was conducted using 194 study participants recruited from lecturers at Dire Dawa University in Ethiopia 116 female and 78 were males aged 29.23. The following five labels are used: Department head in general, efficient male Department head, efficient female Department head, inefficient male Department head, and inefficient female Department head) were responded to by the research participants. Seven different hypotheses were tested using ANOVA. Findings revealed that gender role orientation had a significant effect on the evaluation of the Department head. Furthermore, there were no significant effects of gender, and attachment of labels on the evaluation of Department head and no interaction effects of gender and gender role orientation, gender and attachment of labels and gender, gender role orientation, and attachment of labels on the evaluation of Department head.
\end{abstract}

Keywords: Gender, gender role, Dire Dawa, evaluation, Department head.

\section{Introduction}

Numerous studies have been conducted to measure the impact of gender beliefs on the evaluation of male and female employees in a variety of workplaces. [1] Such courses address various positions in the workplace and the performance of those who occupy different positions. There have been countless studies of men and women in management positions and people's perceptions of their performance. [2]

The same behaviors of men and women are often interpreted differently because the observers paste different labels of the same behaviors performed by men and women. One reason for this is sexual fantasies. Gender beliefs have many meanings but the most common features among all of these definitions are: segregation / consensus / shared / shared / belief / expectations / psychological organizations / ideas / about characteristics / (personality) traits / character / attributes / attributes given to people on the basis of their gender / by women and men. [3]-[4]

The defeat of the sexual stereotype can have serious consequences, especially for women. When they meet a person for the first time, people automatically give a sexually explicit personality to that person, whether it is true or not, because that person is in a group of men or women. [5] Traditionally paid work was seen as a man's domain. Although this is no longer available, the speculative model still exists. In particular, the leadership position continues to be defined by the characteristics given as masculine.

Research shows that a female leader will be defined differently for her personality, and may find a subtle bias than a male leader. [6] Evidence exists that the epidemic of open bias at various levels and decisions about the advancement of men and women is declining, with women leaders still facing barriers associated with secrecy in their efforts to influence. 
As the number of women in positions of responsibility increases and organizations place more emphasis on diversity, the next change in women's perceptions as leaders are expected. In all samples, there was general agreement on the characteristics of the management but there was little agreement on the characteristics of the women. They also found that men were less likely to say that women were more likely to be an effective manager than women. Respondents with previous prior experience and female managers often rate women at the top of management indicators. [4]-[7]

A survey of successful male and female managers about liking was tested. The findings showed that both the values of successful female managers and successful male managers were similar to those of the preferred managers; which means that both successful male executives and successful female managers are seen as the most common traits given to beloved managers. In contrast to the masculine-minded manager, the results often show that the ideal manager's thinking is to be a successful male manager and a successful female manager. [5]-[8]

The effect of gender and different management labels on management evaluations and found that there was no significant effect on gender in management ratings, management features/labels did not significantly affect management ratings, similarly, there was no significant effect of gender and management labeling on leadership ratings. [9]

The current study, therefore, aims to determine whether the gender of the Head of Department, the gender of the teaching inspectors, the depth of the role of the inspectors, and the labels linked to the head of the Department will significantly affect their adherence by followers (i. E. Teachers)

Based on the above mentioned, we, therefore, state the following hypotheses:

1. There will be a significant gender impact on the assessment of the head of the Department.

2. There will be a significant impact of focusing on the role of gender in the assessment of the head of the Department.

3. It will have a significant effect on the attachment of labels to the examination by the head of the Department

4. There will be the implementation of gender and gender co-operation in the assessment of the head of the Department

5. There will be the implementation of gender co-operation and the attachment of labels to the assessment of the head of the Department.

6. There will be a working-class collaboration on gender roles and the labeling of labels for examination by the head of the Department.

7. There will be gender operational co-operation, gender roles directing, and labeling of examinations at the head of the Department.

\section{Material and Methods}

Participants: One hundred and ninety-four lecturers, from the University of Direct Dawa, participated in the study. One hundred and sixteen (116) female teachers and seventy-eight (78) males aged 29.23 in the study were used. The method of randomized trial evaluation in which respondents were randomly selected was used for this study. 
Instruments: Five variants were used in this study, respondents were asked to describe the class leaders in general, the head of the male department, the head of the male department, the head of the women's department, and the head of the women's department. Personal information such as age, gender, and the department was also available.

Procedure: Copies of the questions were provided by the lecturers of the University of Dire Dawa. The first section measured the details of the respondents. These include age, gender, and age. The researcher himself presented a list of questions to the respondents, thanking them for their participation. There were 5 variations of the questions provided. Respondents were unaware that there were five variations available.

Statistical Analysis: Data collected in the field were analyzed using descriptive and varied statistics. Seven hypotheses produced were analyzed using ANOVA. The Statistical Package for Social Sciences (SPSS) was used for data analysis to ensure accuracy.

\section{Result and Discussions}

Table 1: ANOVA summary showing significant impact on gender interaction, gender participation, and label attachment in examinations head of Department

\begin{tabular}{|l|l|l|l|l|l|}
\hline Source & Sum of mean & Mean square & df & F & P \\
\hline Gender(G) & 67.7500 & 67.7500 & 1 & 0.0400 & $>.0500$ \\
\hline Nomination Type (N) & 7756.2800 & 1939.0700 & 4 & 1.0800 & $>.0500$ \\
\hline $\begin{array}{l}\text { Gender role orientation } \\
(\mathrm{GR})\end{array}$ & 57271.6200 & 19090.5400 & 3 & 10.6400 & $<.0500$ \\
\hline G X N & 5818.4800 & 1454.6200 & 4 & 0.8100 & $>.0500$ \\
\hline G X GR & 6993.4200 & 2331.1400 & 3 & 1.3000 & $>.0500$ \\
\hline N X GR & 23483.4600 & 1956.9600 & 12 & 1.0900 & $>.0500$ \\
\hline G X N X GR & 9605.7300 & 1067.3000 & 9 & 0.6000 & $>.0500$ \\
\hline Error & 270689.5800 & 1792.6500 & 151 & & \\
\hline Total & 392797.2800 & & 187 & & \\
\hline
\end{tabular}

The results of the statistical analysis revealed that there was no significant sexual impact on the examination of the head of the Department $[\mathrm{F}(1,187)=.04, \mathrm{P}>.05]$. However, there has been a significant impact on the role of gender in the evaluation of the head of the Department [F ( 3 , $187)=10.64, \mathrm{P}<.05]$. There was no significant effect of label attachment on the Department's head test $[\mathrm{F}(4,187)=1.08, \mathrm{P}>.05]$. There was also no significant effect on the interaction of gender and gender roles in the examination of the head of the Department $[\mathrm{F}(3,187)=1.30, \mathrm{P}>$ .05]. Similarly, there was no significant effect on gender interaction and label attachment in the Department's head examination $[\mathrm{F}(4,187)=.81, \mathrm{P}>.05]$. There were no significant results of the association of label attachments and gender status in the Department's head examination [F $(12,187)=1.09, \mathrm{P}>.05]$. Similarly, there was no significant effect on gender interaction, label attachment, and gender roles in the Department's head examination $[\mathrm{F}(9,187)=.60, \mathrm{P}>.05]$.

\section{Discussions}

The results of the study indicate that there was no significant impact on the evaluation of the head of the Department, so a single hypothesis is rejected. 
The second Hypothesis, which stated that there would be a significant impact on the selection of gender roles in the assessment of class leaders, is confirmed. This suggests that gender equality contributes to the assessment of the head of the Department.

The third hypothesis that there will be a significant effect of the labeling of the labels on the test of the leaders (leaders) has been rejected. This suggests that no labels 'male functioning,' "dysfunctional male," "dysfunctional woman," "dysfunctional woman" or "department head in general" influence the examination of topics. This could be a result of the fact that only good labels were used in the course, and, in the present study, direct and negative labels were tested.

Inconsistent with the findings of this study is a common indication in the existing literature that even though male and female managers were considered successful, men still saw more successful male leaders than successful female leaders as essential elements of effective leadership.

A fourth hypothesis stating that there will be a cooperative effect of gender roles in the examination of the head of the Department is also rejected.

The Fifth Hypothesis that tested the effectiveness of gender interactions and the attachment of labels to examination by the head of the Department was also rejected.

The findings of the study also found that there was no effect on the interaction of gender roles and the labeling of labels in the Department's head examination, and therefore six hypotheses were also rejected. This may be due to the exposure of research participants in identifying women in leadership positions at the university.

The seventh Hypothesis was also rejected as the findings of the study indicated that there was no impact on gender interaction, gender roles, and the labeling of labels in the Department's head examination.

\section{CONCLUSION}

The study investigated the impact of gender, gender roles, and the labeling of labels on examinations by the head of the Department. The results of this study revealed that gender did not significantly affect the assessment of the head of the Department. The gender of the visual and visual person has therefore no effect on the examination of the head of the Department.

Guidance on the role of gender is found to be important in the assessment of the head of the Department. There is a significant difference between males and androgyny (40.06), and males with no comparison (48.04) in the examination of the head of the Department. There is also a significant difference between females and females (27.32), and androgyny and males (40.06). Significant differences in definitions also exist between the undivided and masculine (48.04), and the non-feminine (-27.32).

The attachment of labels, such as male function, male function, female function, and female function, also did not significantly affect the examination of the head of the Department.

There was also no integration of gender interactions and a focus on gender roles in the evaluation of the head of the Department.

Also, no interaction results were found for sex and label attachments. The direction of the gender role and the attachment of the labels did not affect the assessment of the head of the Department.

Finally, there were no gender gaps, gender roles consideration, and label labeling in the Department's head examination.

The result of this study would be the result of exposure from the university environment where the study respondents were found. The insignificance of gender may be because respondents were exposed to men and women in positions of leadership at the university. For 
example, almost every department in a university has female teachers in its staff, and respondents are no longer surprised that women are in leadership positions.

\section{RECOMMENDATION}

Almost all research conducted to investigate the impact of gender on assessing the head of the Department used academics or university lecturers receiving formal education to measure leaders. It is therefore recommended that in the future, people who do not have formal leadership should be used as study participants to have a basis for comparing between leaders and nonhuman leaders in their ratings of the head of the Department.

And during this study, most of the participants who used it were reluctant to participate in the study depending on the length of the questionnaire used. It is therefore also recommended that in the future, a short questionnaire be developed to save participants time and raise their interest in the questionnaire.

\section{References}

[1].Biswas, P. K., Roberts, H., \& Stainback, K. (2021). Does women's board representation affect non - managerial gender inequality?. Human Resource Management.

[2]. Tabassum, N., \& Nayak, B. S. (2021). Gender stereotypes and their impact on women's career progressions from a managerial perspective. IIM Kozhikode Society \& Management Review, 2277975220975513.

[3]. Salin, D. (2011). The significance of gender for third parties' perceptions of negative interpersonal behavior: Labelling and explaining negative acts. Gender, Work \& Organization, 18(6), 571-591.

[4].Stoker, J. I., Van der Velde, M., \& Lammers, J. (2012). Factors relating to managerial stereotypes: The role of gender of the employee and the manager and management gender ratio. Journal of Business and Psychology, 27(1), 31-42.

[5].Hamidullah, M. F., Riccucci, N. M., \& Pandey, S. K. (2015). Women in city hall: Gender dimensions of managerial values. The American Review of Public Administration, 45(3), 247-262.

[6].Kmec, J. A., \& Skaggs, S. L. (2014). The "state" of equal employment opportunity law and managerial gender diversity. Social Problems, 61(4), 530-558.

[7].Ruiz-Jiménez, J. M., del Mar Fuentes-Fuentes, M., \& Ruiz-Arroyo, M. (2016). Knowledge combination capability and innovation: The effects of gender diversity on top management teams in technology-based firms. Journal of business ethics, 135(3), 503515.

[8].Rowley, S., Hossain, F., \& Barry, P. (2010). Leadership through a gender lens: How cultural environments and theoretical perspectives interact with gender. International Journal of Public Administration, 33(2), 81-87.

[9].Fischbach, A., Lichtenthaler, P. W., \& Horstmann, N. (2015). Leadership and gender stereotyping of emotions. Journal of Personnel Psychology. 